\title{
Enfermedad de Lesch-Nyhan
}

Dr. Germán Schlager C. ${ }^{1}$, Dra. Marta Colombo C. ${ }^{2}$ Dr. Yves Lacassie S.3*

\section{Lesch-Nyhan disease}

We report on a case of classical Lesch-Nyhan disease whose diagnosis was confirmed through specific fibroblast differential growth assay. This technique also allowed us to establish that the mother and one of het sisters were carriers and to detect a severely affected male by prenatal diagnosis in the sister. Current metabolic basis, clinical findings and therapeutic trials in this disorder are reviewed. The importance of these studies for appropriate genetic counseling in families with this rare but severe disease is stressed.

(Key words: Lesch-Nyhan disease, hypoxantine-guanine phosphoribosyltransferase deficiency, X-linked recessive disorder, diagnostic tests, carrjer detection, prenatal diagnosis).

La enfermedad de Lesch-Nyhan es un error congénito del metabolismo de las purinas, cau. sado por una mutación de un gen estructural ubicado en el cromosoma $X$, de herencia recesiva, que determina un déficit de la enzima hipoxanti-

1. Neurólogo Infantil.

2. Unidad de Neuropsicología, INTA, Universidad de Chile.

3. Cinidad de Genética, INTA, Univer sidad de Chile.

* Parte de este trabajo fue presentado en el XV Coneresa Nacional de Pediatría. La Serena. 1984. na-guanina-fosforibosil-transferasa (HFRT). Fue descrita por Lesch y Nyhan en $1964^{1}$, en dos hermanos que presentaban compromiso del sistema nervioso central (SNC) grave y niveles anormales de ácido úrico. Aunque hay una publicación sobre esta rara enfermedad en nuestro medio ${ }^{2}$, nos ha parecido de interés revisar el tema enfatizando nuevos aspectos y presentar un caso en que el diagnóstico fue confirmado a través de cultivos diferenciales, que permitieron, además, determinar el estado de portadora (heterocigota) en la madre y una tía, en la cual además se hizo diagnóstico prenatal de esta afección. 


\section{Caso Clínico}

Paciente varón de 6 años de edad, producto del segundo embarazo, de evolución normal. Nació por cesárea, a las 41 semanas de gestación, por presentación podálica, pesaba $2.640 \mathrm{~g}$, su talla era $46,5 \mathrm{cr}$ y ja circunferencia craneana $33 \mathrm{~cm}$. No hubo asfixia ni otros problemas perinatales. Este paciente consultó por primera vez al año de edad por retraso del desarrollo psicomotor: había tenido sonrisa social a los 5 meses, aún no afjrmaba la cabeza ni se sentaba solo. El primer embarazo de la madre terminó en aborto espontaneo al tercer mes y el feto tenía malfor. maciones múltiples; después del nacimiento del probando ocurrió un nuevo aborto espontáneo. La madre tenía un hermano que falleció en la segunda década de la vida con manifestaciones clínicas similares al probando y dos hermanas. aparentemente sanas, una casada con un hijo normal y otra soltera (Fig. 1). En el examen físico mostraba espasticidad, distonías muscula. res y circunferencia de cráneo disminuida $(43 \mathrm{~cm}$ $<2 \%$ Nellhaus). En e] electroencéfalograma habian anormaliđades inespecúticas y actividad irritativa occipital: tomografía computarizada de cráneo normal; aminoaciduria y aminoacidemia normales.

A la edad de 4 años mostraba escaso progreso en el desarrollo psicomotor, retraso del crecimiento (P y T $<5 \%$ NCHS), microcefalia discreta ( $<1 \%$ Nellhaus), espasticidad, hiperreflexia, signo de Babinsky bilateral, distonias, irritabilidad, lesiones con pérdida de tejido en manos y labios (Fig. 3) y, desde hacía alrededor de un año, había desarrollado gran autoagresividad con automutilación. A pesar del dolor, se mordía manos y labios en forma compulsiva, repetida $y$ persistente, produciéndose heridas graves con pérdida de tejido, por lo que debían mantenerlo con guantes y restringirle la movilidad de los brazos. Dos uricemias resultaron elevadas: $7,26 \mathrm{y}$ $10,40 \mathrm{mg} x \mathrm{~d} 1$. Se tomó una biopsia de piel para medir la enzima HFRT en fibroblastos: e] estudio, realizado en la Universidad de Johns Hopkins, U.S.A., mostró proliferación de los fibroblastos en medio 6 - tioguania (6TG) y no en medio hipoxantina-adeninatimina (HAT), resultado consistente con una deficiencia total de actividad de HFRT. Junto con la muestra del probando se enviaron biopsias de la madre (III-2) y de una de las tías (III-3): los fibroblastos maternos crecieron en ambos medios, demostrando que, además de células normales, tenía una población de células resistentes a la $6 \mathrm{TG}$, lo que confirmaba su condición de portadiora. Los fíbroblastos de la tía crecieron sólo en el medio normal. La hiperuricemia se trató con dieta

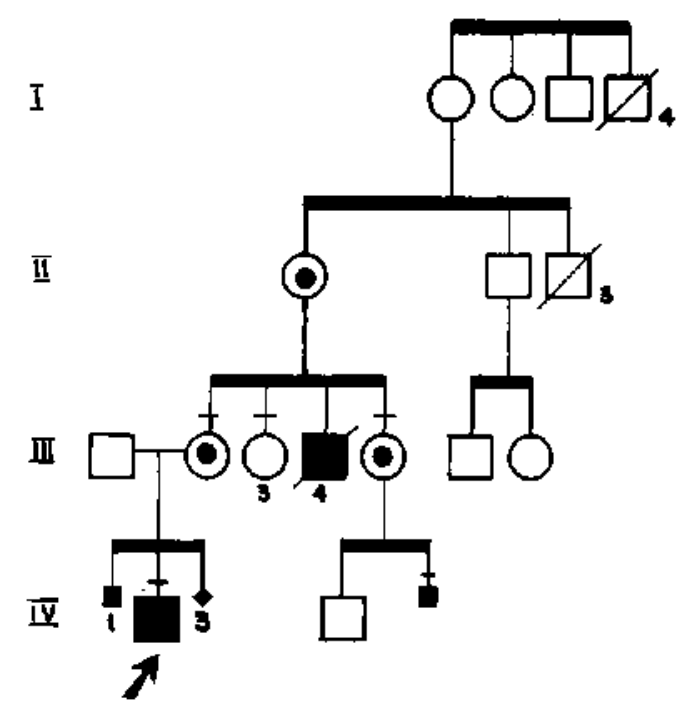

Figura 1. Genealogia. I murió a los 40 años con historia de epilepsia. $\mathrm{JI}_{3}$ también murió a los 40 años. III-3 soltera. III-4 murió a los 17 an̄os con afección similar a la del probando, con retraso mental y automutilación. IV-1 aborto con malformaciones congénitas. La flecha indica el probando; los cuadrados ltenos a los hombres afectados; los círculos con punto interior a las portadoras (heterocigotas) obligadas; la barra transversal sobre el símbolo los que han sido estudiados.

restringida en ácjdo úrico y allopurinol. Su đisfunción neurológica se ha tratado con diazepam y haloperidol sólo con resultados transitorios. Se le diseñó una placa dental de acrílico que le impide morderse (Fig. 2).

En los últimos años ha demostrado algunos avances en su desarrollo, logrando buen control. de cuello $y$ tronco, siendo capaz de mantenerse sentado sin apoyo, por breve tiempo. Como no camina es movilizado en silla de ruedas. Su vocabulario es de 12 a 15 palabras y tiene disartria. Su conducta de autoagresividad y automutilación ha disminuido pero se exacerba en situaciones de mayor exigencia o ansiedad. Tiene buen contacto social y excelente relación con sus familiares. Por el momento no ha presentado otras evidencias de hiperuricemia.

\section{DISCUSION}

La enfermedad de Lesch-Nyhan, en su forma clásica, no debiera constituir un problema diagnóstico si se tiene presente el tipo de herencia, sus manifestaciones clínicas y el aporte de algunos exámenes de laboratorio $2,3,5,7$.

Entre las consecuencias bioquímicas más notables en la forma clásica de esta enfermedad, están la defíciencia marcada de la enzima HFRT y un 


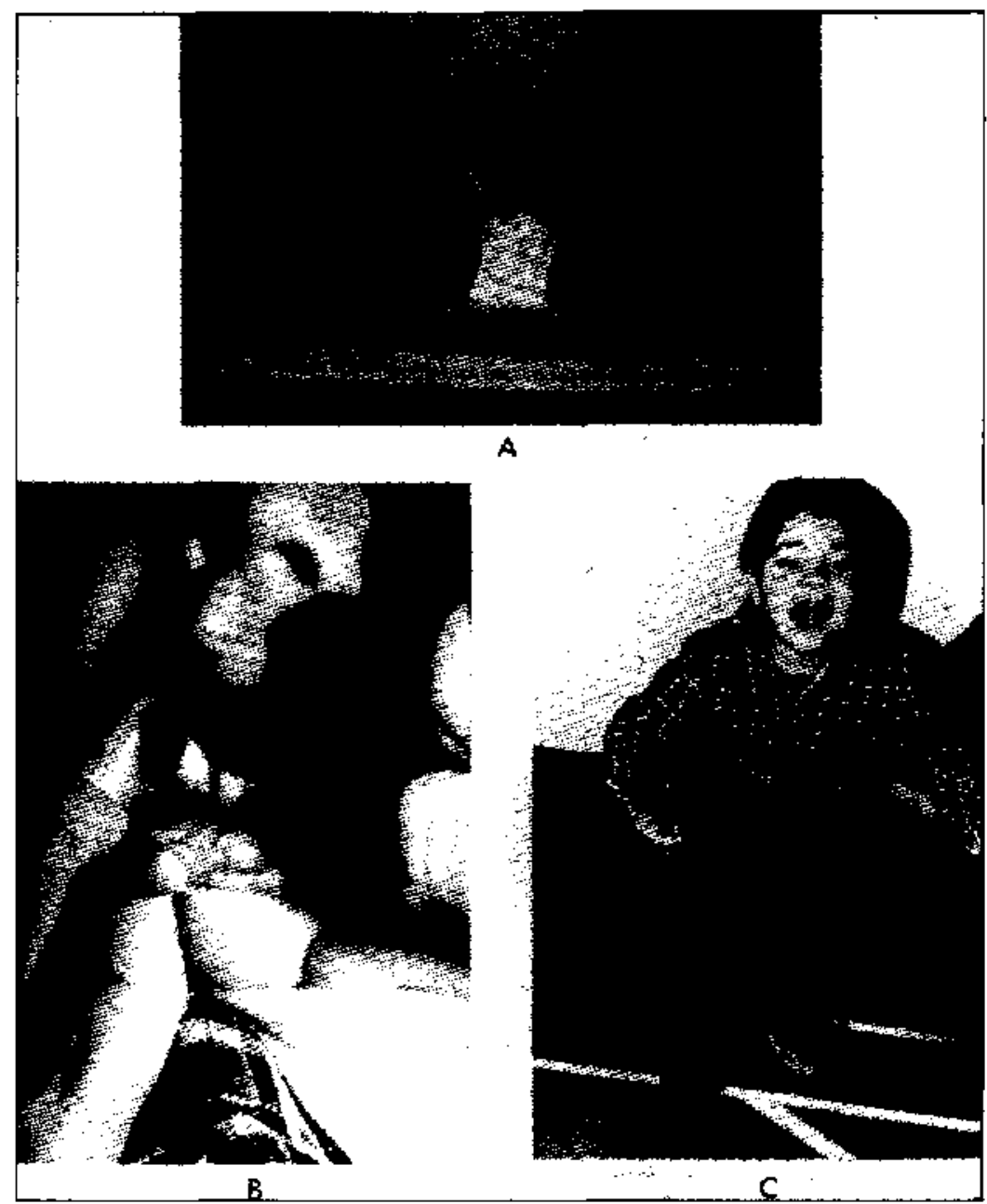

Figura 2. A) El probando a los 4 años, con sus manos enguantadas y tela protectora sobre el labjo inferior. B) lesiones de automutilación en al labio inferior. C) a los 5 años con la placa dental para evitar se muerda. Nótese que áin es incapaz de mantenerse sentado solo.

gran aumento de la concentración de áciđo úrico en sangre $y$ orina, que-en la sangre alcanza concentraciones de 8 a $25 \mathrm{mg} \mathrm{x}$ dl (normal 2 a $5,5 \mathrm{mg} \mathrm{x} \mathrm{dl}$ ). La HFRT, se encuentra en todos los tejidos - pero en mayor concentración en los nutcleos de la base del cerebro-, permite la conversión de hipoxantina en guanina, ácido guanílico y ácido intosînico. Su ausencia obliga a degradar toda la hipoxantina en ácido úrico, aumentando 20 veces la actividad metabólica de esta vía. La relación existente entre el déficit enzimático y la hiperuricemia aún no se comprende bien (Fig. 3), sin embargo, en la actualjdad, se presume que la falta de HFRT produciria un aumento de 5 fosforibolsil-1-pirofosfato (FPPF), lo que estaría relacionado con la sobreproducción de purinas ${ }^{3-5}$. Esta enfermedad se manifiesta clínicamente sólo en hombres. Son niños que presentan un periodo de recién nacido sin complicaciones, desarrollàndose normalmente los primeros 6 a 8 meses de vida. El síntoma más precoz es habitualmente ta presencia de sedimento anaranjado en la orina, que tiñe los pañales $y$, en algunos casos, hematuria con litiasis del tracto uninario. Sin embargo, en la mayoría de los casos, las primeras manifestaciones detectadas son las relacionadas con el SNC. Alrededor de los 6 meses de edad el desarrollo parece detenerse. Posteriormente el lactante pierde algunas de las habilidades logradas, como afirmar la cabeza o sentarse solo. En un comienzo aparece hipotonía, con hiperreflexia tendinosa y signo de Babinsky, luego distonía, movimientos coreoatetósicos, disfagia, disartria, tendencia a la posición en opistótono. El diagnóstico que comúnmente se plantea en este período es el de parálisis cerebral, 


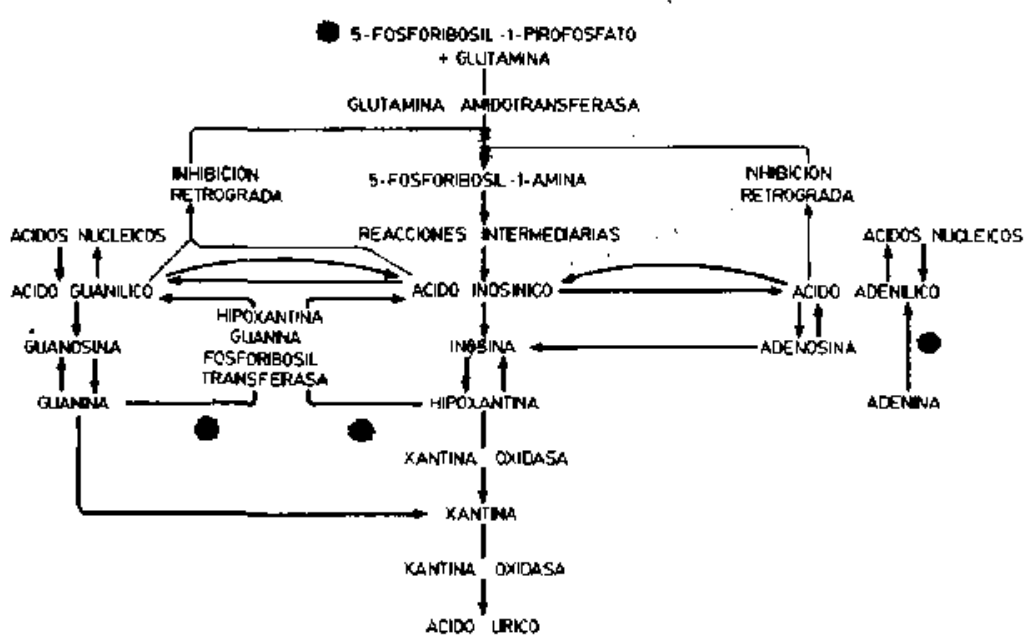

Figura 3. Vía metabólica de las purinas en relación a la enfermedad de Lesch-Nyhan. Un mecanismo regulatorio importante es la inhibición de la FRPF-glutamina amidotransferasa por los nucleótidos de la purina y sus polifosfatos.

La primera etapa en la reacción señalada probablemente es límitante en la sintesis de purinas. La hipoxantina-guanina-fosforibosiltransferasa (HFRT) también usa el sustrato fosforibosil pirofosfato (FRPF) (señalado por $\bullet$ y compite con la enzima limitante FRPF-glutamina amidotransferasa.

Niños con la enfermedad de Lesch - Nyhan ticnen concentraciones tisulares elevadas de FRPF (tomado de Sawiman y Wright ${ }^{5}$ ).

con evidente mayor compromiso motor que mental.

Alrededor de los 2 años de edad aparece, como síntoma característico y único de esta enfermedad, la autoagresión con automutilación. Es una conducta compulsiva que lleva a la producción de heridas con pérdida de tejido, especialmente de labios. lengua y manos. En algunos niños mayores se han observado conductas agresivas con otras personas, incluyendo el uso de palabras soeces; una vez que cometen esta agresión, se arrepienten y tratan de pedir excusas. La capacidad intelectual (CI) varía ampliamente, siendo su CI promedio de 58 , con us rango entre 25 y $101^{6}$. El desarrollo mental es aparentemente mayor que lo que se puede evaluar por el grave compromiso motor' que estos pacientes tienen.

La deambulación es imposible, los pacientes quedan confinados a silla de ruedas y al uso de inmovilizaciones parciales de las extremidades superiores para evitar la automutilación. La ma. yoria de los enfermos logra desarrollar cierto contacto social y algún grado de lenguaje, aunque éste es disártrico y difícil de comprender. La mayoría de estos niños presentan además tetraso del crecimiento, permaneciendo generalmente bajo el percentil 3 de peso y talla. A medida que van creciendo, desarrollan manifestaciones simi. lares a los adultos con gota, presentando hematu. ria, cristaluria, cálculos renales y dolores tipo cólicos. Se han observado también tofos en las orejas y, después de la primera década, artritis gotosa aguda. Los pacientes fallecen habitualmente entre los 10 y 30 años de edad, por insuficiencia renal ${ }^{1-3,6,7}$.

El diagnóstico debe plantearse frence a las malformaciones clinicas descritas 6 y al hallazgo de concentraciones elevadas de ácido úrico en sangre y orina. Se confirma con el estudio de la actividad de la enzima. HRFT en cultivo de fibroblastos. Con esta técnica, también es posible hacer el diagnóstico de portadora y diagnóstico prenatal $^{3.8}$.

La hiperuricemia se trata con alopurinol (10 $\mathrm{mg} \times \mathrm{kg}$ peso $\mathrm{x}$ día), recomendándose además una ingestión elevada de líquidos $(50 \mathrm{ml} x$ $\mathrm{kg}$ peso/dia). Si bien este tratamiento es efectivo en el manejo de todas las manifestaciones comunes a la gota, previniéndose la artritis y la nefropatía, este medicamento no modifica la đisfunción neurológica. Para esta alteración se ha intentado usar diazepam, haloperidol, hidroxitriptofano y combinaciones como carbidopa, imipramina e hidroxitriptofano. Ultimamente se han publicado los efectos beneficiosos de la flufenazina especialmente sobre la autoagresión $3,6,7,9$. Con este mismo fin también se han utilizado diversas terapias conductuales ${ }^{6,7}$. Sin embargo, ninguno de los tratamientos descritos ha demostrado ser de gran efectividad, por lo que la prevención, a través de la detección de porta. doras, consejo genético y diagnóstico prenatal, 
contınua siendo lo más importante ${ }^{3}$.

Todas las genealogías muestran un patrón de herencia consistentemente recesivo ligado al cromosoma $X$. En la familia presentada existía el antecedente del hermano de la madre fallecido a los 17 años con una afección semejante a la del probando; además, el estudio realizado en la madre demostró en forma categóriça su condición de heterocigota, consistente con la hipótesis de Lyon. A trayés de los estudios de detección de heterocigotas, que también pueden hacerse mediante electroforesis de proteina de los folículos pilosos se ha visto que menos de $10 \%$ de los casos aislados corresponden a nuevas mutaciones y no el tercio esperado ${ }^{3}$. Esta enfermedad debiera investigarse en todo lactante que comience con retraso del crecimjento y retraso del desarrollo psicomotor en sus primeros meses, en el que exista el antecedente de aparición precoz de sedimento anaranjado en la orina, especialmente notorio si están deshidratados. Aunque lá mayoría de los pacientes presentan hiperuricemia, especialmente en las etapas posteriores de la enfermedad, una uricemia normal no descarta el diagnóstico, dado que es normal en 5 a $10 \%$ de los pacientes. Una prueba simple de rastreo consiste en medir la relación entre el contenido de ácido úrico y el de creatinina en la primera orina de la mañana ${ }^{3}$. Si el diagnóstico no se hace precozmente y la enfermedad ha seguido su curso, el diagnóstico debiera ser planteado en todo niño con parálisis cerebral mixta (espasticidad y coreoatetosis). La parición de automutilación y autoagresión es patognomónica. Aunque la autoagresiridad es una conducta relativamente común en niños con retardo mental grave, nunca adquiere las características tan dramáticas de esta enfermedad, en la que hay gran automutilación. Fue la aparición de esta manifestación la que, en este caso, nos hizo plantear el diagnóstico. Para confirnar el diagnóstico y proporcionar un pronóstico y un consejo genético precisos es muy importante medir la enzima HFRT en fibroblastos y no en eritrocitos, pues la enzima es muy inestable $y$ hay discrepancias entre ambos estudios ${ }^{10}$, siendo invariablemente más alta en fibroblastos ${ }^{3}$.

Aunque existen diferentes técnicas enzimológicas y de biologia molecular que, usando enzimas de restricción y sondas de DNA, permiten el análisis del DNA y demostrar una heterogeneidad considerable en las mutaciones de esta enzi$\mathrm{ma}^{3,11,12}$, desde el punto de vista práctico, la técnica de crecimiento diferencial en medios especiales permite detectar y separar poblaciones celulares con y sin actividad de HFRT donde pueden hacerse las determinaciones pertinentes. Así se ha visto que pacientes con deficiencia parcial de HFRT presentan síntomas atenuados. Se han intentado correlacionar las manifestaciones clinicas con la cantidad de actividad de la HFRT: si la actividad es $<1,5 \%$ se manifestaria la enfermedad clásica, que es la que hemos descrito: si es de. 1,5 a $8 \%$ los afectados tendrían hiperuricemia, alteraciones neurológicas pero inteligencia normal y falta de automutilación, y s1 la actividad es de 8 a $60 \%$ sólo se produciría hiperuricemia ${ }^{10}$. En nuestro probando había prácticamente ausencia total de la enzima, lo que concuerda con el síndrome clásico y florido que presenta. La técnica de crecimiento diferencial es relativamente sencilla, requiriéndo disponer de los medios de cultivos diferenciales: 6-tioguanina (6TG) o 6-azoguanina y HAT. Los fibroblastos cultivados se hacen crecer en ambos medios. En el caso del paciente con Lesch-Nyhan sus fibroblastos no crecen en el medio HAT y sí en el medio 6TG, dado que todas sus células son HFRT negativas (ó 6TG resistentes) y no toman e] análogo de la purina. Los fibroblastos de personas normales crecen en el medio HAT y no en el $6 \mathrm{TG}$, pues al ser incorporado por la célula normal resulta en muerte celular. En las portadoras, que tienen dos poblaciones celulares, se obtiene crecimiento en ambos medios, pudiendo determinatse directamente la actividad HFRT en cada una de ellas. Como se ha mencionado, esta técnica, además de detectar portadoras permite el diagnóstico prenatal de esta afección. Poco después de realizar los estudios serĩalados en el probando, su madre. y una tia, otra tía del paciente (Fig. 1, III-5) consultó solicitando consejo genético, por presentar embarazo de 16 semanas no planificado, a pesar del empleo de un dispositivo uterino. Ella no había aceptado realizarse biopsia de fibroblastos por cuanto tenía un niño normal (IV-4) y no deseaba tener más hijos por el eventual riesgo involucrado. Se le realizó cultivo de fibroblastos y amniocentesis, los que mostraron que era portadora, el feto era de sexo masculino $(46, X Y)$ y afectado, presentando un déficit absoluto de HFRT ${ }^{11} 13$. En los últimos años, concomitante al desarrollo de técnicas de biología molecular, la biopsia de vellosidades coriales ha producido un avance notable en el diagnóstico prenatal de muchas afecciones, al permitir el diagnóstico a las 8 ó 9 semanas de gestación. Recientemente se ha descrito el diagnóstico prenatal de la Enfermedad de Lesch-Nyhan, en el primer trimestre, utilizando esta técnica ${ }^{12}$. El haber podido establecer con certeza el diagnóstico de esta enfermedad, determinar el estado heterocigoto y realizar diagnóstico prenatal, constituye un avance fundamental en el consejo genético de ésta y otras enfermedades graves, que desafortunadamente no tienen 
tratamientos específicos.

\section{RESUMEN}

Se presenta un caso de Enfermedad de Lesch-Nyhan típico, cuyo diagnóstico fue confirnado a través de técnicas de crecimiento celular diferencial. Esta técnica permitió también establecer la condición de portadora en la madre y una de las tías en la que se realizó el diagnóstico prenatal de un nuevo caso. Se revisan algunos aspectos clínicos, metabólicos y terapéuticos de interés, enfatizando la importancia de los estudios diagnósticos específicos para el consejo genético adecuado de familias con esta rara pero grave enfermedad.

\section{AGRADECIMIENTOS}

Se agradece a la Dra. Barbara Migeon, de la Unidad de Genética, Departamento de Pediatría, Johns Hopkins Hospital, Baltimore, USA, la contribución al estudio de esta familia.

\section{REFERENCIAS}

1. Iesch, M.. Nyhon, W.: A familial disorder of uric acid metabolism and central nervous system function. Am. J. Med. 36: 561, 1964.

2. Chernilo, $S$., Puga, F., Aspillago, M., Avendaño, 1 .: Síndrome de Lesch-Nyhan. Rev, Chit. Pediatr. 53: 460, 1982 .
3. Seegmiller, J.E.: Disorders of purine and pyrimidine metabolism. In: Principles and Practice of Medical Genetics. (Ed) Emery, A.E.H. and Rimoin, D.L. Churchill Livingston, London, 1983. Vol. 2, Cap. 90: $1286-1305$.

4. Rosenbloom, F.M., Kelly, W.N.: Enzyme defect associated with a sex-linked human neurological disorder and excessive purine synthesis. Science 155: 1682,1967 .

5. Swaiman, K.F., Wright, F.J.: The practice of pediatric neurology ( 2 Ed). C.V. Mosby, St. Lou is, 1982.

6. Christie, R., Bay, C., Kaufman, I., Bekay, B., Borden, M., Nyhan, W.: Lesch-Nyhan disease: clinical experience with nineteen patients. Develop. Med. Child. Neurol. 24: 293, 1982.

7. Nyhan, $W_{*}$. The Lesch-Nyhan sy ndrome. Develop. Med, Child, Neurol. 20: 376, I978.

8. Migeon, B.R., Det Kaloustian, V.M., Nyhan, W.L. Young, W.J., Childs, B.: X-tinded hypoxanthineguanine phosphoribosyltransferase deficiency: heterozygote has two clonal populations. Science 160: 425,1968 .

9. Dasheiff, R.: Benzodiazepine treatment for Lesch-Nyhan syndrome. Develop. Med, Child. Neurol. 22: 101, 1980

10. Hersh, J.H., Hand, M.E., Page, T., Seegmiller, E. Nyhan, W., Weisskopf. B.: Clinical correlations in partial hypoxanthine guanine phosphoribosyltransferase deficiency. Am. J. Hum. Genet, 37: A58, 1985 .

11. Máseon, B.: Comu nùcación personal, 1984.

12. Gibbs, D.A., MCFadyen, I.R., Crawfurd, M., De Muinck Keizer, E.E., Head-House-Benson, C.M., wilson, T.M., Farront, P.H.: First-trimester diagnosis of Lesch--Nyhan syndrome, Lancet 24: 11, 1984

13. Varas, J., Iglesias, J, Schlager, G., Colombo, M. Lacassie, Y.: Manuscrito en preparación. 1986. 